\title{
Quantitative iTRAQ-based proteomic analysis of differentially expressed proteins in aging in human and monkey
}

\author{
Hao Wang ${ }^{1,2}$, Xiaoqi Zhu², Junyan Shen², En-Feng Zhao ${ }^{2}$, Dajun $\mathrm{He}^{3}$, Haitao Shen ${ }^{3}$, Hailiang Liu ${ }^{2,3^{*}}$ (D) and \\ Yongxin Zhou ${ }^{1 *}$
}

\begin{abstract}
Background: The underlying physiological mechanisms associated with aging are still complex and unclear. As a very important tissue of human body, the circulatory system also plays a very important role in the process of aging. In this study, we use the isobaric tags for relative and absolute quantification (iTRAQ) method to identify differentially expressed proteins in plasma for humans and monkeys between young and aged. Western blotting and behavioral experiment in mice were performed to validate the expression of the candidate protein.
\end{abstract}

Results: Between the young / the old humans and the young / the old monkeys 74 and 69 proteins were found to be differently expressed, respectively. For the human samples, these included 38 up-regulated proteins and 36 down-regulated proteins (a fold change $\geq 1.3$ or $\leq 0.667, p$ value $\leq 0.05$ ).For the monkey samples, 51 up-regulated proteins and 18 down-regulated proteins (a fold change $\geq 1.3$ or $\leq 0.667, p$ value $\leq 0.05$ ). KEGG pathway analysis revealed that phagosome, focal adhesion, ECM-receptor interaction and PI3K/AKT signaling pathway were the most common pathways involved in aging. We found only IGFBP4 protein that existed in up-regulated proteins in aged both for human and monkey. In addition, the differential expression of IGFBP4 was validated by western blot analysis and IGFBP4 treatment mimicked aging-related cognitive dysfunction in mice.

Conclusions: This first, the integrated proteomics for the plasma protein of human and monkey reveal one proteinIGFBP4, which was validated by western blotting and behavioral analysis can promote the process of aging. And, iTRAQ analysis showed that proteolytic systems, and inflammatory responses plays an important role in the process of aging. These findings provide a basis for better understanding of the underlying mechanisms involved in aging.

Keywords: Plasma, Quantitative proteomics, iTRAQ, IGFBP4, Cognitive dysfunction

\section{Background}

Aging, which is broadly defined as the time-dependent functional decline that affects most living organisms, has attracted curiosity and excited imagination throughout the history of humankind [1]. Nowadays, aging is known as a physiological process encompassing several body changes at macroscopic and microscopic levels throughout an organism's lifespan. Heart, brain, and muscle are considered as the most efficient model systems or tissues

\footnotetext{
*Correspondence: hailiang_1111@tongji.edu.cn; Zhou6302@tongji.edu.cn

${ }^{2}$ Translational Center for Stem Cell Research, Tongji Hospital, Tongji

University School of Medicine, Shanghai 200065, China

'Department of Thoracic-Cardiovascular Surgery, Tongji Hospital, Tongji

University School of Medicine, Shanghai, China

Full list of author information is available at the end of the article
}

with the ability to affect aging and lifespan [2-5]. Through the study of various age-related diseases, such as Alzheimer's disease, hypertension, and Parkinson's disease, links between these age-related diseases and these model systems have been established [6, 7]. There are several factors, such as genomic instability, telomere attrition, epigenetic alterations, loss of proteostasis, deregulated nutrient sensing, mitochondrial dysfunction, cellular senescence, stem cell exhaustion, and altered intercellular communication, involved in the progression of aging $[1,2]$. Nevertheless, due to the complexity of the molecular mechanisms involved in aging, we have not yet fully explained the causes, processes, and relationships between them.

(c) The Author(s). 2019 Open Access This article is distributed under the terms of the Creative Commons Attribution 4.0 International License (http://creativecommons.org/licenses/by/4.0/), which permits unrestricted use, distribution, and reproduction in any medium, provided you give appropriate credit to the original author(s) and the source, provide a link to the Creative Commons license, and indicate if changes were made. The Creative Commons Public Domain Dedication waiver (http://creativecommons.org/publicdomain/zero/1.0/) applies to the data made available in this article, unless otherwise stated. 
Many previous studies have revealed differences between older and younger species at both the biological and molecular levels [1]. A large mountof evidence indicates that tumor necrosis factor $\alpha$ (TNF- $\alpha)$, a Transforming growth factor (TGF)-secreted factor superfamily member, and ubiquitination and ubiquitin-like family proteins may play critical roles in the progression of aging [8-10]. Some differentially expressed genes involved in the process of aging have been revealed by microarray-based whole-genome gene expression analyses [11]. A comprehensive and in-depth study of proteomics will help us to better understand the mechanism of aging.

Tissue-based quantitative clinical proteomics has emerged as an unbiased discovery tool to study the mechanisms of various diseases [12]. Although many targeted investigations of aging have been designed to examine specific pathways that are significant to this phenomenon [13, 14], few studies have focused on the expression landscape of overall proteins in plasma, especially for human and monkey. However, plasma, an important component of the blood which has the central and integrating role in human physiology, can reflect the physical condition of an individual [15]. For mice, some systemic factors in plasma can affect cognitive function, either positively by promoting neurogenesis, or negatively by reducing neurogenesis [16-19]. Therefore, we compared the differentially expressed proteins in plasma between young and aged subjects using iTRAQ-based quantitative proteomics to gain information to understand the mechanism of aging at the protein level.

\section{Results}

\section{Characteristics of the clinical study}

We collected plasma samples from eight humans and eight monkeys. The human and monkey samples were equally divided into four different groups based on their age. There was a significant difference in age between the young and the aged. $(p<0.05)$. Table 1 shows the detailed information of the samples.

\section{ITRAQ quantification of plasma protein profiles}

We employed iTRAQ labeling technology in combination with LC-MS/MS to investigate differentially expressed proteins in circulating blood between the aged and young groups. In total, 485 and 708 proteins were identified to be commonly expressed in human and monkey samples, respectively (Fig. 1a and Additional file 1: Figure S1A). These proteins were subjected to further analysis. Among the 485 identified human proteins, approximately $98 \%$ were more than $10 \mathrm{kDa}$ (Fig. 1b). Approximately 95\% of peptides were between 6 and 24 amino acid residues in length (Fig. 1c). Of the identified proteins, more than $62 \%$ had sequence coverage above $10 \%$ (Fig. 1d). More than $88 \%$ of the proteins contain less than 10 peptides, and the number of proteins decreases with the increase in the number of matching peptides (Fig. 1e).

For monkey samples, among the 708 identified proteins, approximately $98 \%$ were more than $10 \mathrm{kDa}$ (Additional file 1: Figure S1B). Approximately $96 \%$ of peptides were between 6 and 24 amino acid residues in length (Additional file 1: Figure S1C). Of the identified proteins, more than $44 \%$ had sequence coverage above 10\% (Additional file 1: Figure S1D). More than $90 \%$ of the proteins contain less than 10 peptides, and the number of proteins decreases with the increase in the number of matching peptides (Additional file 1: Figure S1E).

The subcellular localizations, molecular functions, and biological processes of identified proteins were analyzed by GO annotation. For human samples, extracellular region $(14.18 \%)$, cell part $(13.83 \%)$, cell (13.83\%) and organelle $(10.08 \%)$ were the most representative cell component classifications among the identified proteins (Fig. 2a). In terms of molecular functions, the most representative groups of the identified proteins were binding (48.46\%), catalytic activity (20.79\%), and enzyme regulator activity (9.08\%) (Fig. 2b). In biological processes,single-organism process (9.64\%), cellular process $(8.94 \%)$, biological regulation (8.24\%), response to stimuli (8.21\%), metabolic process $(8.1 \%)$ were the most representative of the processes (Fig. 2c).

In monkey samples, cell part (15.52\%), cell (15.52\%), organelle (12.29\%) and extracellular region (9.33\%) were the most representative cell component classifications among the identified proteins (Additional file

Table 1 Characteristics of aged and young samples in this study

\begin{tabular}{|c|c|c|c|c|c|c|}
\hline & \multicolumn{3}{|l|}{ Human } & \multicolumn{3}{|l|}{ Monkey } \\
\hline & Aged & Young & $P$ value & Aged & Young & $P$ value \\
\hline Health Status & Health & Health & I & Health & Health & I \\
\hline Age (year), mean (SD) & $87.25,9.287$ & $26.25,2.986$ & $<0.0001$ & $21.75,4.425$ & $7.5,1.291$ & 0.0008 \\
\hline \multirow[t]{2}{*}{ Female } & $86.00,8.485$ & & & $21.5,6.364$ & & \\
\hline & & / & 0.8446 & & / & 0.9348 \\
\hline Male & $88.50,13.44$ & & & $22.0,4.243$ & & \\
\hline
\end{tabular}




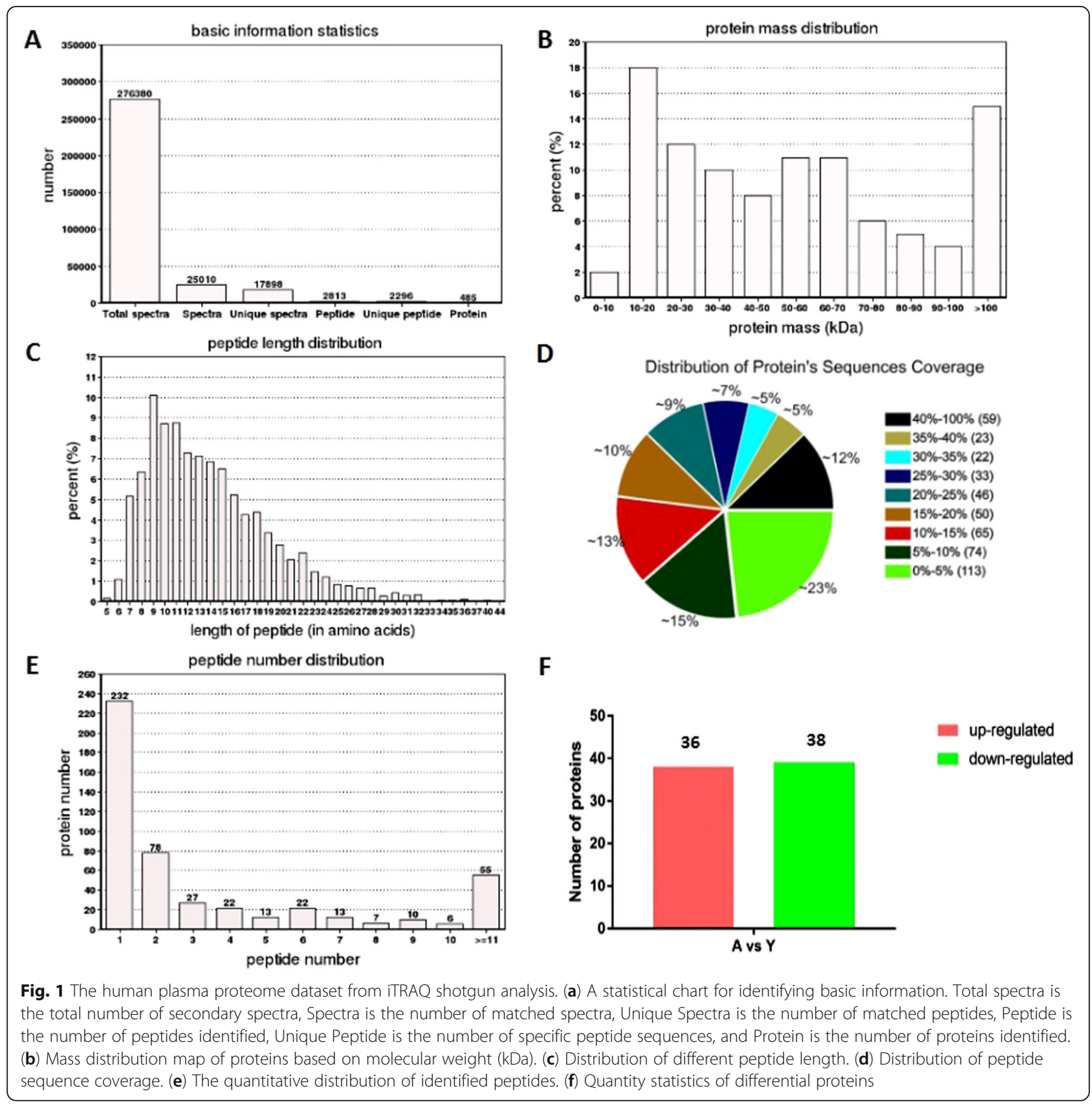

2: Figure S2A). In terms of molecular functions, the most representative groups of the identified proteins were binding $(47.72 \%)$, catalytic activity (21.16\%), structural molecule activity (8.25\%) and enzyme regulator activity (7.69\%) (Additional file 2: Figure S2B). In biological processes, cellular process $(9.71 \%)$ singleorganism process $(9.56 \%)$, metabolic process $(8.49 \%)$, biological regulation (7.86\%), regulation of biological process $(7.34 \%)$ and response to stimuli $(7.23 \%)$ were the most representative of the processes (Additional file 2: Figure S2C).
Differential levels of plasma proteins between aged and young samples

For the human samples, of the 485 identified proteins, 38 were up-regulated (ratio Aged/Young $\geq 1.3, p<0.05$ ) and 36 were down-regulated (ratio Aged/Young $\leq 0.667$, $p<0.05$ ) (Tables 2 and 3). For the monkey samples, of the 708 identified proteins, 51 were up-regulated (ratio Aged/Young $\geq 1.3, p<0.05)$ and 18 were down-regulated (ratio Aged/Young $\leq 0.667, p<0.05$ ) (Additional file 3: Table S1 and Additional file 4: Table S2). Although the similarity of the differentially expressed proteins in 
A

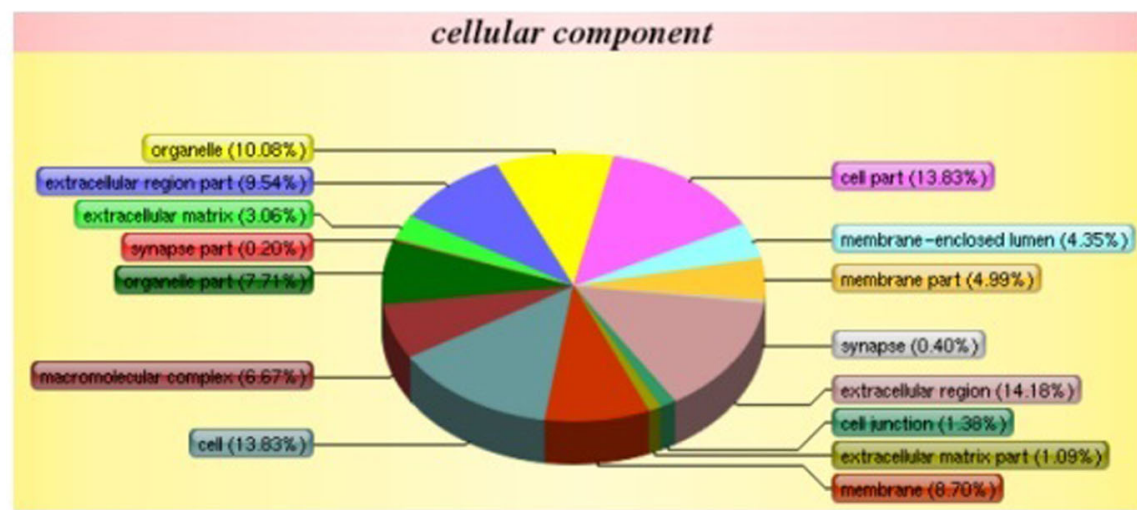

B

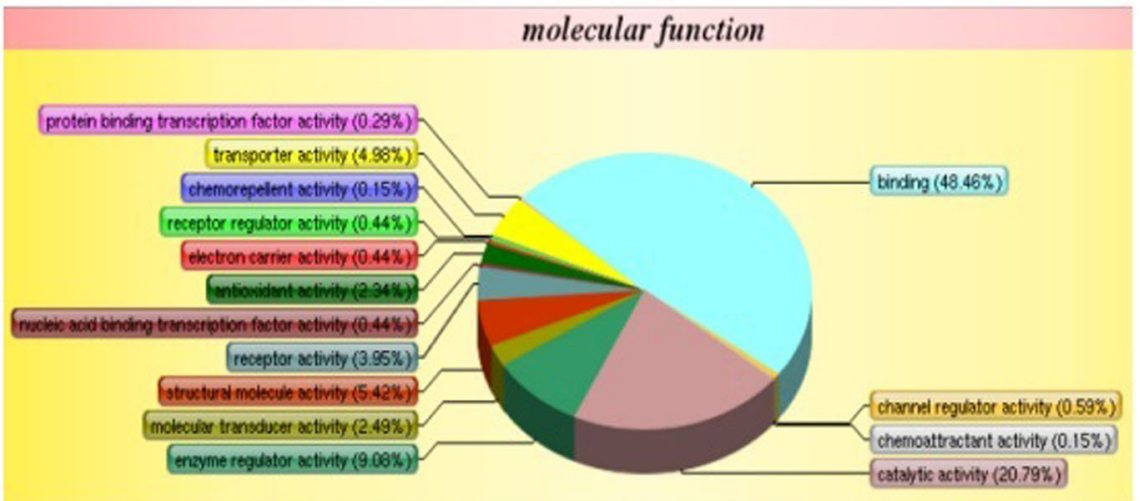

C

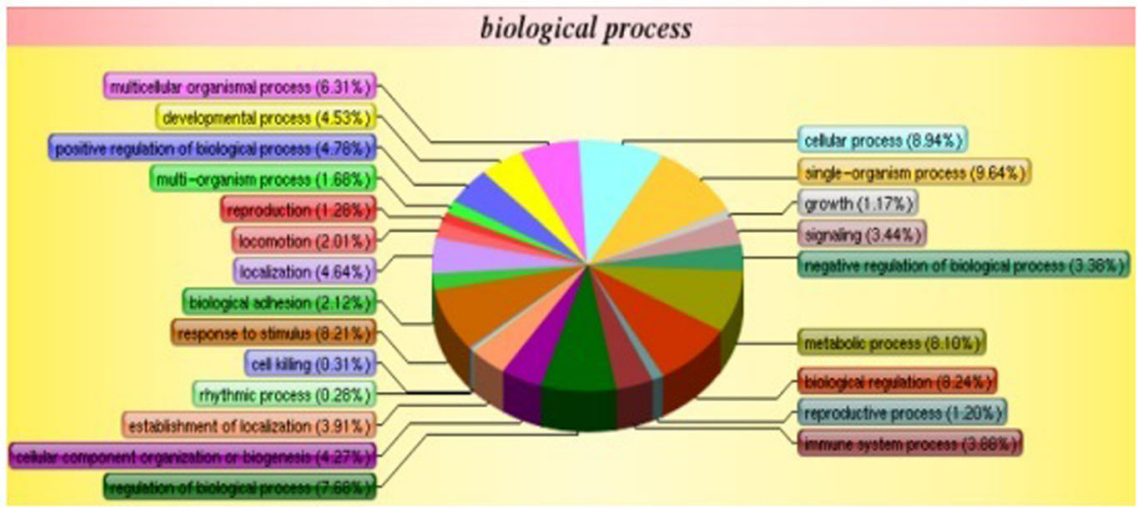

Fig. 2 Gene ontology (GO) annotation and functional classification of identified serum proteins from all human samples. GO terms for cellular compartment (a), molecular function (b), and biological process (c)

humans and monkeys was not high, we found only IGFBP4 protein that existed in up-regulated proteins in aged both for human and monkey. Then it was focused for subsequent analysis.

\section{KEGG pathway analysis of differentially expressed proteins}

In human aged samples, differentially expressed plasma proteins were mainly enriched in three pathways, while in young plasma samples, differentially expressed plasma proteins were mainly enriched in seven pathways by KEGG pathway analysis. These included Pathogenic
Escherichia coli infection, ECM-receptor interaction, Phagosome, Focal adhesion, PI3K-Akt signaling pathway and PPAR signaling pathway (Fig. 3).

\section{Validation of ITRAQ results in individual subjects}

To confirm the accuracy of our iTRAQ results, a key component that triggers senescence in young MSC [20], IGFBP4, was selected for further study. Consistent with the results of the data in the Table 2 and Additional file 3: Table S1, the protein level of IGFBP4 was significantly upregulated in the aged group compared with the young group (Fig. 4). 
Table 2 Up-regulated proteins, identified in aged of human

\begin{tabular}{|c|c|c|c|c|c|c|}
\hline Number & Accession & Protein symbol & Description & Gene symbol & Mean \pm SD & E_Value \\
\hline 1 & Q15113 & PCOC1 & Procollagen C-endopeptidase enhancer 1 & PCOLCE & $1.92 \pm 0.53$ & 0 \\
\hline 2 & P05090 & APOD & Apolipoprotein D & APOD & $1.58 \pm 0.3$ & 1.00E-95 \\
\hline 3 & Q9UHG3 & PCYOX & Prenylcysteine oxidase 1 & PCYOX & $1.58 \pm 0.51$ & 0 \\
\hline 4 & P03950 & ANGl & Angiogenin & ANG & $1.49 \pm 0.41$ & $1.00 \mathrm{E}-73$ \\
\hline 5 & 076076 & WISP2 & WNT1-inducible-signaling pathway protein 2 & WISP2 & $1.89 \pm 0.62$ & 5.00E-89 \\
\hline 6 & P00450 & CERU & Ceruloplasmin & CER & $1.28 \pm 0.34$ & 0 \\
\hline 7 & P0CG05 & LAC2 & Ig lambda-2 chain $C$ regions & $\operatorname{lgG}$ LC & $1.34 \pm 0.28$ & $5.00 \mathrm{E}-54$ \\
\hline 8 & P07988 & PSPB & Pulmonary surfactant-associated protein B & SFTPB & $1.44 \pm 0.42$ & 0 \\
\hline 9 & Q86UD1 & OAF & Out at first protein homolog & OAF & $1.47 \pm 0.4$ & 1.00E-141 \\
\hline 10 & Q9HDC9 & APMAP & Adipocyte plasma membrane-associated protein & APMAP & $1.7 \pm 0.83$ & 0 \\
\hline 11 & P05160 & F13B & Coagulation factor XIII B chain & F13B & $1.46 \pm 0.5$ & 0 \\
\hline 12 & P27918 & PROP & Properdin & CFP & $2.53 \pm 0.27$ & 0 \\
\hline 13 & P06727 & APOA4 & Apolipoprotein A-IV & APOA & $1.64 \pm 0.36$ & 0 \\
\hline 14 & P02745 & C1QA & Complement $\mathrm{C} 1 \mathrm{q}$ subcomponent subunit $\mathrm{A}$ & C1QA & $1.23 \pm 0.24$ & 7.00E-126 \\
\hline 15 & P22692 & IBP4 & Insulin-like growth factor-binding protein 4 & IGFBP4 & $1.51 \pm 0.33$ & 4.00E-126 \\
\hline 16 & P07357 & $\mathrm{CO} A \mathrm{~A}$ & Complement component C8 alpha chain & $\mathrm{C} 8 \mathrm{~A}$ & $1.79 \pm 0.23$ & 0 \\
\hline 17 & O00187 & MASP2 & Mannan-binding lectin serine protease 2 & MASP2 & $2.69 \pm 0.98$ & 0 \\
\hline 18 & P02749 & $\mathrm{APOH}$ & Beta-2-glycoprotein 1 & $\mathrm{APOH}$ & $1.32 \pm 0.26$ & $2.00 \mathrm{E}-108$ \\
\hline 19 & Q9NZP8 & C1RL & Complement $\mathrm{C} 1 \mathrm{r}$ subcomponent-like protein & C1RL & $2.07 \pm 0.18$ & 0 \\
\hline 20 & P48740 & MASP1 & Mannan-binding lectin serine protease 1 & MASP1 & $2.57 \pm 0.99$ & 0 \\
\hline 21 & P05164 & PERM & Myeloperoxidase & MPO & $2.24 \pm 0.82$ & 0 \\
\hline 22 & Q15485 & FCN2 & Ficolin-2 & FCN2 & $2.52 \pm 0.65$ & $6.00 \mathrm{E}-158$ \\
\hline 23 & P26927 & HGFL & Hepatocyte growth factor-like protein & MST1 & $1.51 \pm 0.42$ & 0 \\
\hline 24 & P01876 & $|\mathrm{GHA}|$ & Ig alpha-1 chain $C$ region & DKFZp686K18196 & $1.85 \pm 0.9$ & 0 \\
\hline 25 & P02788 & TRFL & Lactotransferrin & LTF & $3.3 \pm 1.16$ & 0 \\
\hline 26 & P07360 & CO8G & Complement component C8 gamma chain & C8G & $1.4 \pm 0.15$ & $2.00 \mathrm{E}-103$ \\
\hline 27 & P36980 & FHR2 & Complement factor $\mathrm{H}$-related protein 2 & CFHR2 & $4.84 \pm 1.31$ & $3.00 \mathrm{E}-137$ \\
\hline 28 & P02743 & SAMP & Serum amyloid P-component & APCS & $2.1 \pm 0.23$ & 4.00E-129 \\
\hline 29 & Q03591 & FHR1 & Complement factor H-related protein 1 & CFHR1 & $2.41 \pm 0.55$ & 0 \\
\hline 30 & Q99969 & RARR2 & Retinoic acid receptor responder protein 2 & RARRES2 & $1.43 \pm 0.25$ & 4.00E-91 \\
\hline 31 & P01859 & IGHG2 & Ig gamma- 2 chain $C$ region & DKFZp686104196 & $1.9 \pm 0.92$ & $2.00 \mathrm{E}-180$ \\
\hline 32 & Q96KN2 & CNDP1 & Beta-Ala-His dipeptidase & CNDP1 & $1.36 \pm 0.15$ & 0 \\
\hline 33 & P01764 & HV303 & Ig heavy chain V-III region VH26 & $\mathrm{VH} 3$ & $2.28 \pm 1.04$ & 4.00E-40 \\
\hline 34 & Q03591 & FHR1 & Complement factor H-related protein 1 & FHR-1 & $3.66 \pm 2.08$ & $8.00 \mathrm{E}-15$ \\
\hline 35 & 000602 & FCN1 & Ficolin-1 & FCN1 & $2.81 \pm 0.92$ & 0 \\
\hline 36 & Q16769 & QPCT & Glutaminyl-peptide cyclotransferase & QPCT & $1.82 \pm 0.73$ & 0 \\
\hline 37 & P61628 & LYSC & Lysozyme C & LYZ & $3.61 \pm 1.21$ & $2.00 \mathrm{E}-82$ \\
\hline 38 & P48740 & MASP1 & Mannan-binding lectin serine protease 1 & DKFZp686M0562 & $1.88 \pm 0.49$ & $6.00 \mathrm{E}-51$ \\
\hline
\end{tabular}

\section{IGFBP4 impaired cognitive performance of mice}

It is well recognized that aging can be accompanied by cognitive impairment. To evaluate the effects of IGFBP4 on cognitive performance, through tail vein injection at a does of $2.67 \mu \mathrm{g} / \mathrm{kg}$, once every other day over the course of 1 month, into mice with 8 months ages, 13 mices were divided into two groups: Control group $(n=6)$ and IGFBP4 group $(n=7)$, we examined mice in the Morris water maze. During the test time, there was no significant difference between the two groups in swimming speed (Fig. 5a). Although there was no significant difference between the two groups, the duration 
Table 3 Down-regulated proteins, identified in aged of human

\begin{tabular}{|c|c|c|c|c|c|c|}
\hline Number & Accession & protein symbol & Description & gene symbol & Mean \pm SD & E_Value \\
\hline 1 & Q76FE5 & $\mathrm{H} 2 \mathrm{~B}$ & Histone $\mathrm{H} 2 \mathrm{~B}$ & ABCF2 & $0.31 \pm 0.1$ & $6.00 \mathrm{E}-28$ \\
\hline 2 & Q13201 & MMRN1 & Multimerin-1 & MMRN1 & $0.77 \pm 0.18$ & 0 \\
\hline 3 & P08571 & CD14 & Monocyte differentiation antigen CD14 & CD14 & $0.48 \pm 0.04$ & 0 \\
\hline 4 & P13796 & PLSL & Plastin-2 & HEL-S-37 & $0.19 \pm 0.08$ & 0 \\
\hline 5 & P05556 & ITB1 & Integrin beta-1 & ITGB1 & $0.42 \pm 0.03$ & 0 \\
\hline 6 & P02776 & PLF4 & Platelet factor 4 & PF4 & $0.48 \pm 0.17$ & $2.00 \mathrm{E}-40$ \\
\hline 7 & Q6Q788 & APOA5 & Apolipoprotein A-V & APOA5 & $0.75 \pm 0.14$ & 0 \\
\hline 8 & Q96PD5 & PGRP2 & $\mathrm{N}$-acetylmuramoyl-L-alanine amidase & PGLYRP2 & $0.46 \pm 0.14$ & 0 \\
\hline 9 & P08697 & A2AP & Alpha-2-antiplasmin & SERPINF2 & $0.51 \pm 0.13$ & 0 \\
\hline 10 & Q9UK55 & ZPI & Protein Z-dependent protease inhibitor & SERPINA10 & $0.38 \pm 0.1$ & 0 \\
\hline 11 & P19823 & $\mathrm{ITIH} 2$ & Inter-alpha-trypsin inhibitor heavy chain $\mathrm{H} 2$ & $\mathrm{ITH} 2$ & $0.65 \pm 0.08$ & 0 \\
\hline 12 & P02760| & $\mathrm{AMBP}$ & Protein AMBP & $\mathrm{AMBP}$ & $0.38 \pm 0.09$ & 0 \\
\hline 13 & Q96KK5 & $\mathrm{H} 2 \mathrm{~A} 1 \mathrm{H}$ & Histone $\mathrm{H} 2 \mathrm{~A}$ type $1-\mathrm{H}$ & HIST1H2AG & $0.49 \pm 0.07$ & $2.00 \mathrm{E}-54$ \\
\hline 14 & P04275 & WWF & von Willebrand factor & WWF & $0.48 \pm 0.08$ & 0 \\
\hline 15 & P12111 & CO6A3 & Collagen alpha-3(VI) chain & COL6A3 & $0.43 \pm 0.09$ & 0 \\
\hline 16 & Q9UGM5 & FETUB & Fetuin-B & FETUB & $0.24 \pm 0.04$ & 0 \\
\hline 17 & P15169 & CBPN & Carboxypeptidase N catalytic chain & CPN1 & $0.71 \pm 0.12$ & 0 \\
\hline 18 & P22792 & CPN2 & Carboxypeptidase N subunit 2 & CPN2 & $0.7 \pm 0.2$ & 0 \\
\hline 19 & Q5XIF6 & TBA4A & Tubulin alpha-4A chain & TUBA4A & $0.83 \pm 0.18$ & 0 \\
\hline 20 & P29622 & KAIN & Kallistatin & SERPINA4 & $0.2 \pm 0.07$ & 0 \\
\hline 21 & P05452 & TETN & Tetranectin & CLEC3B & $0.43 \pm 0.02$ & 4.00E-116 \\
\hline 22 & P35858 & ALS & Insulin-like growth factor-binding protein complex acid labile subunit & IGFALS & $0.58 \pm 0.14$ & 0 \\
\hline 23 & P04196 & HRG & Histidine-rich glycoprotein & HRG & $1.76 \pm 0.63$ & 0 \\
\hline 24 & Q13790 & APOF & Apolipoprotein F & APOF & $1.40 \pm 0.43$ & 0 \\
\hline 25 & P55058 & PLTP & Phospholipid transfer protein & PLTP & $1.39 \pm 0.11$ & 0 \\
\hline 26 & P04070 & PROC & Vitamin K-dependent protein C & LOC & $1.87 \pm 0.64$ & $2.00 \mathrm{E}-35$ \\
\hline 27 & P01764 & HV303 & Ig heavy chain V-III region VH26 & IGHV3-49 & $1.32 \pm 0.24$ & $5.00 \mathrm{E}-42$ \\
\hline 28 & O95445 & APOM & Apolipoprotein M & APOM & $1.40 \pm 0.25$ & 2.00E-110 \\
\hline 29 & P06702 & S10A9 & Protein S100-A9 & S100 & $3.10 \pm 1.59$ & $6.00 \mathrm{E}-62$ \\
\hline 30 & Q5R1X3 & ACTB & Actin, cytoplasmic 1 & LOC & $2.23 \pm 0.62$ & 0 \\
\hline 31 & P05543 & THBG & Thyroxine-binding globulin & SERPINA7 & $2.26 \pm 0.56$ & 0 \\
\hline 32 & P04278 & SHBG & Sex hormone-binding globulin & SHBG & $3.77 \pm 0.14$ & 4.00E-171 \\
\hline 33 & P10720 & PF4V & Platelet factor 4 variant & PF4V1 & $1.35 \pm 0.31$ & $6.00 \mathrm{E}-33$ \\
\hline 34 & P00748 & FA12 & Coagulation factor XII & F12 & $1.69 \pm 0.70$ & 0 \\
\hline 35 & P36955 & PEDF & Pigment epithelium-derived factor & SERPINF1 & $1.45 \pm 0.26$ & 0 \\
\hline 36 & P19827 & $\mathrm{ITIH} 1$ & Inter-alpha-trypsin inhibitor heavy chain $\mathrm{H} 1$ & $\mathrm{ITIH} 1$ & $2.16 \pm 0.16$ & 0 \\
\hline
\end{tabular}

time in the quadrant where the platform was previously placed that the IGFBP4 group spent was less than the control group (Fig. 5b). Meanwhile, compared with the control group, the mice of the IGFBP4 group also significantly reduced the number of times they crossed over the previous position of the platform (Fig. 5c). Moreover, the IGFBP4 group showed a significant increase in the time getting to the stage for the first time compared with the control group (Fig. 5d). These results demonstrated that IGFBP4 could aggravate the dysfunction of cognitive ability in mice.

\section{Discussions}

Aging is a phenomenon that results from a complex interaction of diverse factors. The mechanisms underlying aging are very intricate and many factors such 
A

\section{Signific ant differential genes enriched pathways in young samples}

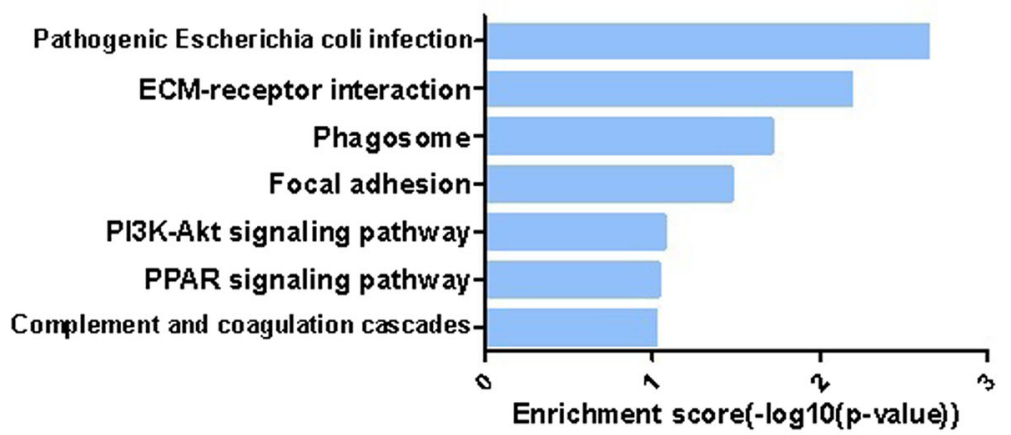

B

\section{Significant differential genes enriched pathways} in aged samples

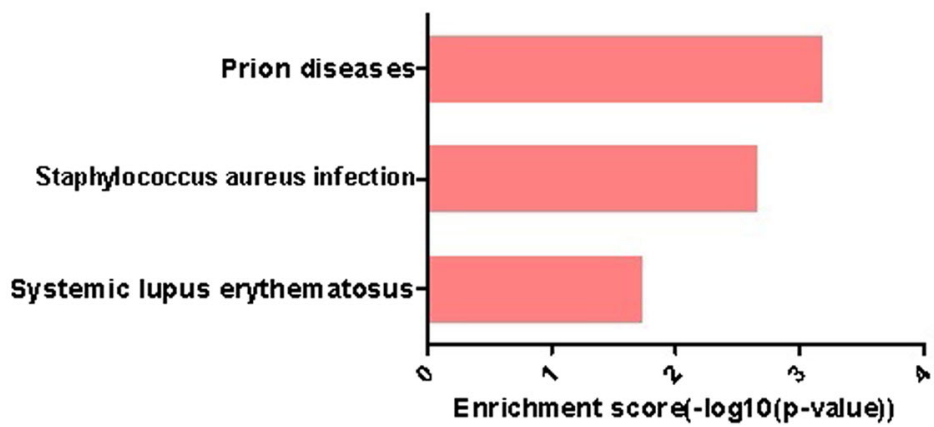

Fig. 3 KEGG pathway analysis of differentially expressed proteins in human samples. (a) Significant differential genes enriched pathways in young samples. (b) Significant differential genes enriched pathways in aged samples

A

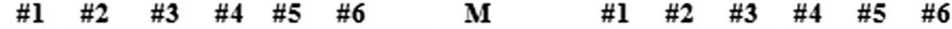

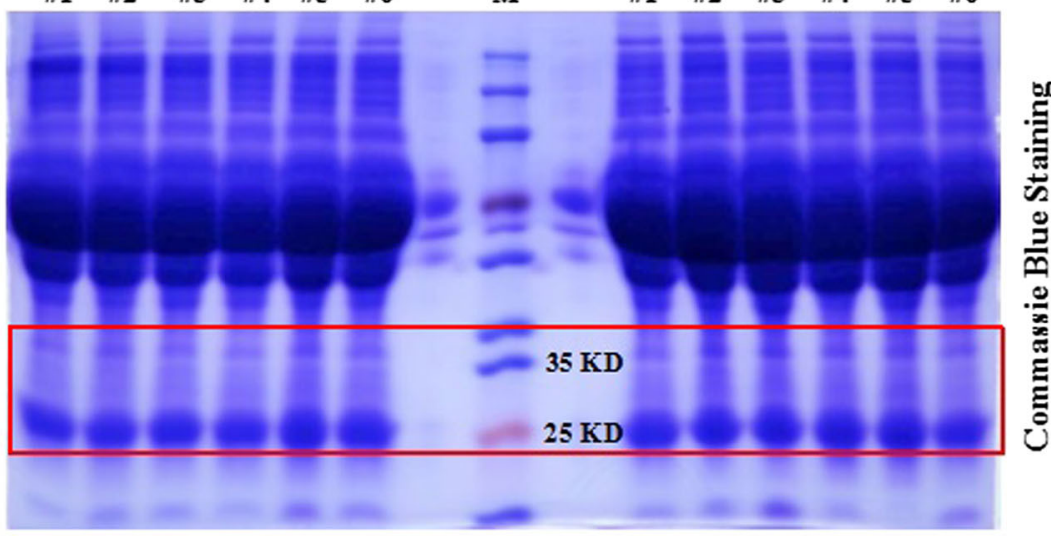

B
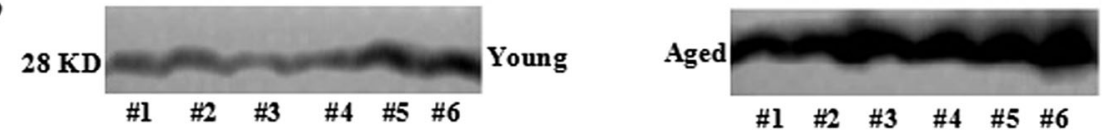

Fig. 4 Expression levels of IGFBP4 revealed by western blotting. (a) Coomassie blue staining of total protein loading; (b) Western blot analysis of IGFBP4 in human young and aged plasma 

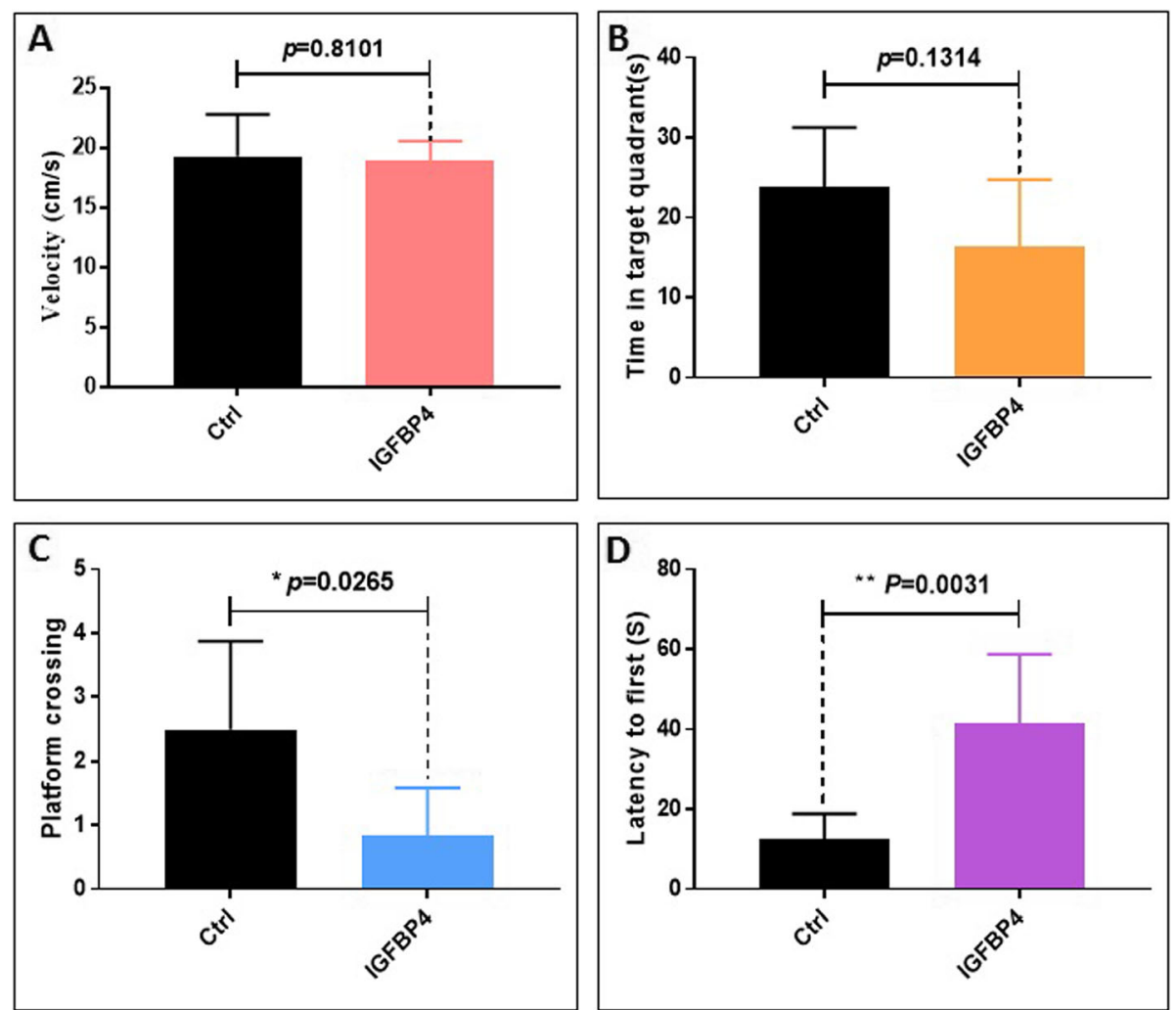

Fig. 5 Morris water maze analysis of behavior of 8 months mice injected with IGFBP4 protein. (a) The swimming speed of the two groups of mice. (b) The time spent in the target quadrant of the two groups of mice $(p=0.1314)$. (c) Number of times the two groups of mice crossed the platform $\left({ }^{*} p<0.05\right)$. (d) The time of the two groups of mice first appeared on the platform $\left.{ }^{* *} p<0.01\right)$

as aging cells and tissue remodeling, telomeres, DNA repair, growth, energy homeostasis, and reproductive function have been implicated in the process of aging [1]. Although many factors related to aging have been identified, the overall mechanism of aging is highly complicated, so specific causes of aging are still unclear. Proteins circulating in the blood are critical for aging; however, the serum proteome from human and monkey has remained largely unexplored. Therefore, studies at the proteome level would help us to better understand the changes in the mechanisms associated with aging.

In our study, 74 proteins and 69 proteins were identified differentially expressed in aged plasma compared with young plasma in human and monkey samples, respectively. Through GO annotation analysis, it was revealed that most of the significant proteins in aging belong to cell parts, extracellular region, and organelle, and mainly participate in the cellular process, metabolic process, and single-organism process. It was revealed that phagosome, complement and coagulation cascades, primary immunodeficiency, dilated cardiomyopathy, and viral myocarditis pathways are the main signaling pathways activated in aging via KEGG pathway analysis, indicating that cardiovascular diseases and inflammatory responses may play a significant role in the process of aging.

\section{Association between IGFBPs and aging}

Insulin-like growth factor I (IGFI) and IGFII are members of the insulin superfamily of growth-promoting peptides and are among the most abundant and ubiquitous polypeptide growth factors. The IGFs are distinguished from insulin by their interaction in circulating blood and the cellular environment with six highaffinity IGF binding proteins (IGFBPs) that have multiple functional properties [21]. In addition to altering the equilibrium between the IGFs and their cell-surface receptors, the IGFBPs can also regulate signaling what is stimulated by other growth factors through their distinct receptors [21].

Almost all members of IGFBP family, such as IGFBP $1 / 2 / 3 / 4 / 5$, are involved in coordinately regulating growth within the physiological context of changing metabolic demands [22]. Several studies have identified that IGFBPs can affect biological responses 
by interacting with cell-surface proteins [22]. IGFBP1 and 2 can modulate cell migration and adhesion by binding to $\alpha 5 \beta 1$ integrin $[23,24]$. IGFBP2 induces activation of the PI3 kinase/AKT pathway through indirect action by binding to a cell-surface receptor termed receptor tyrosine phosphatase beta (RPTP $\beta$ ) $[25,26]$. In addition, IGFBPs are involved in insulin resistance, lipid metabolism, diabetes,carbohydrate metabolism, bone metabolism, and atherosclerosis [22, 27-30].

As a member of IGFBP family, IGFBP4 mainly mediates the cellular signaling by banding to IGF1 that can limit the amount of free IGF in extracellular fluid that is available for receptor activation [22]. IGFBP4 can act as an inhibitor of the canonical Wnt signaling required for cardiogenesis and provides a molecular link between IGF signaling and Wnt signaling [31]. There is evidence that IGFBP4 expression increases with age and is associated with the impairment of MSC differentiation via the Erk and Smad pathway [32]. Consistent with previous studies that indicated IGFBP4 as a key component needed for triggering senescence in young MSC and a harmful factor that impair the habituation learning, which is correlated with cognitive function [20,33], our present study demonstrated that IGFBP4 was up-regulated in the plasma of aged compared with young subjects and that injection of IGFBP4 into mice also accelerates cognitive dysfunction. IGFBP4 also plays a critical role in adipogenesis and loss of IGFBP4 can induce a decrease in adipose tissue [34].

\section{Association between proteolytic systems and aging}

There is growing evidence that normal and pathological aging are often associated with impaired protein homeostasis or proteostasis [35]. Both mechanisms are involved in restoring the structure of misfolded polypeptides and in their removal and degradation, thus preventing the accumulation of damaged components and ensuring the continuous renewal of intracellular proteins [36, 37]. The function of these systems plays a vital role in the survival of cells. Additionally, the accumulation of unfolded, misfolded, or non-degraded proteins is a major factor in the development of some age-related pathologies, such as Alzheimer's disease, Parkinson's disease, and Huntington's disease [38]. Moreover, it has been demonstrated that the activities of the ubiquitin-proteasome system and the autophagylysosomal system, which are the two principal proteolytic systems implicated in protein quality control, decrease with aging $[38,39]$, supporting the view that impaired proteostasis constitutes a common feature of old age.

Regarding autophagy, a double transgenic mouse model in which the amount of the lysosomal receptor for chaperone-mediated autophagy (CMA, one type of autophagy), does not result in an age-dependent decrease in autophagic activity and preserves improved hepatic function with aging [40]. Also, rapamycin, which is an inhibitor of the mTOR pathway, can induce macroautophagy (another form of autophagy different from CMA) to extend median and maximal lifespan of mice [41, 42]. Notably, it had been reported that rapamycin delays multiple aspects of aging in mice [43].

Consistent with the relevance of proteolytic systems in the process of aging, our present study also revealed that the Phagosome pathway plays a key role in the biology of aging. However, although its influence is not obvious in our study, another pathway, Fc gamma receptormediated phagocytosis, is also involved in the process. Therefore, all of the above indicate that aging is involved in perturbed proteostasis, and that experimental perturbation of proteostasis can precipitate age-associated pathologies [1].

\section{Association between inflammation and aging}

In recent years a lot of previous researches found that aging also involves changes at the level of endocrine, neuroendocrine or neuronal intercellular communication [44-47]. Consistent with these results, our present study revealed involvement of Complement and coagulation cascades and Primary immunodeficiency pathway in aging at the protein level. Although the exact mechanism underling aging is still unknown, a prominent aging-associated alteration in intercellular communication, termed "inflammaging" has been widely accepted as a hallmark associated with aging $[48,49]$. Inflammaging may result from multiple causes, such as genetic susceptibility, visceral obesity, microbiota and gut permeability, cellular senescence, impaired recycling and elimination of degraded cellular material, or intrinsic defects in immune cells and chronic infections [8]. Inflammation is also associated with the pathogenesis of obesity and type 2 diabetes, two conditions that contribute to and correlate with aging in the human population [50]. Similarly, defective inflammatory responses play a critical role in atherosclerosis [51]. At the same time, modulating inflammaging as a promising strategy to slow the decline of health that occurs with aging has become more and more widely accepted [8]. Thus, it is reasonable to conclude that pathways related to inflammation play a crucial role in the biology of aging.

\section{Conclusions}

In summary, due to the extremely large dynamic range of plasma proteins and some inherent defects of the iTRAQ $[52,53]$, we did not identify many specific proteins related to aging compered with other subjects $[52,54]$. Our results yet revealed that the differentially expressed IGFBP4 
between aged and young samples is related to the process of aging. In addition,our present study indicated that proteolytic systems and inflammatory responses may play a significant role in the process of aging. Thus, our study suggested a possible relationship between some growth factors, such as IGFBPs, proteolytic systems, and inflammatory responses can affect the process of body aging.. This may provide novel insight into the prevention of aging.

\section{Methods}

\section{Animals}

The mice used in the experiment were all C57BL/6, purchased from Beijing Vital River Laboratory Animal Technology Co., Ltd. Mice were maintained on a $12 \mathrm{~h}$ light/dark schedule, and allowed free access to food and water, following protocols approved by the Animal Research Committee of Tongji Hospital, Tongji University School of Medicine, China. After the test of Morris water maze, the mice were anesthetized with tribromoethanol (Sigma, Saint Louis, USA), then the mice were killed by cervical dislocation.

\section{Sample collection and protein extraction}

For LC-ESI-MS/MS, plasma samples from eight humans and eight Macaca fascicularis monkeys were collected and divided into four groups: Aged-Human (H), Young$\mathrm{H}$, Aged-Monkey $(\mathrm{M})$ and Young- $\mathrm{M}$. The plasma sample from each individual was stored at $-80^{\circ} \mathrm{C}$ for further testing.

To reduce the complexity of samples, the highly abundant proteins were depleted using ProteoMinerTM Kits (Bio-Rad Laboratories, Hercules, CA, USA) according to the manufacturer's protocol. The smaples was added to a mixture of protein lysate, $1 \mathrm{mM}$ PMSF, and $2 \mathrm{mM}$ EDTA. 5 minters later, adding $10 \mathrm{mM}$ DTT. After 15 min of ultrasonic lysis, then centrifuged at $25,000 \times \mathrm{g}$ for $20 \mathrm{~min}$. The supernatant was added 5 times volume of precooled acetone and precipitated at $-20^{\circ} \mathrm{C}$ for $2 \mathrm{~h}$, then centrifuged for $20 \mathrm{~min}$ with $16,000 \times \mathrm{g}$. Follow the previous steps for another precipitation cracking. Then the supernatant was treated with $10 \mathrm{mM}$ DTT for $1 \mathrm{~h}$ at $56^{\circ} \mathrm{C}$, followed by adding $55 \mathrm{mM}$ IAM in a dark room for $45 \mathrm{~min}$. Next, appropriate amount of cold acetone was add to the sample, incubating at $-20^{\circ} \mathrm{C}$ for $2 \mathrm{~h}$. After centrifugation of $25,000 \times \mathrm{g}$ for $20 \mathrm{~min}$, the precipitation was dissolved in $200 \mathrm{uL} 0.5 \mathrm{M}$ TEAB for $15 \mathrm{~min}$ of ultrasonic lysis, followed by another centrifugation of $25,000 \times \mathrm{g}$ for $20 \mathrm{~min}$. The protein concentration of each sample was determined by using the BCA Kit (Sango Bioteh, Shanghai, China).

\section{iTRAQ labeling}

Proteins $(100 \mu \mathrm{g})$ were digested with trypsin (protein: trypsin $=20: 1$; Sigma) and incubated at $37^{\circ} \mathrm{C}$ for $4 \mathrm{~h}$.
More trypsin was then added at the above proportion and incubation continued at $37^{\circ} \mathrm{C}$ for $8 \mathrm{~h}$. The peptides were then dried with a vacuum centrifugal pump and $0.5 \mathrm{M}$ TEAB was used to resolubilize the peptides. Peptides were then labeled with iTRAQ with incubation at room temperature for $2 \mathrm{~h}$ according to the manufacturer's instructions. The labeled peptides were mixed and separated on an SCX column through the LC-20AB liquid phase system (Shimadzu, Kyoto, JPN).

\section{LC-ESI-MS/MS analysis based on TripleTOF 5600}

Each component was redissolved to about $0.5 \mu \mathrm{g} / \mu \mathrm{l}$ in buffer A ( $5 \% \mathrm{ACN}, 0.1 \% \mathrm{FA})$ and centrifuged for $10 \mathrm{~min}$ to remove insoluble matter. Five-microliter samples of each component (about $2.5 \mu \mathrm{g}$ protein) were separated by the LC-20 AD system (Shimadzu, Kyoto Japan). The separation procedure was as follows: first, the sample was transferred to the Trap column over $4 \mathrm{~min}$ at a flow rate of $8 \mu \mathrm{L} / \mathrm{min}$. An analytical gradient with a total flow rate of $300 \mu \mathrm{L} / \mathrm{min}$ was then added to bring the sample into the column. Then the sample was separated and transferred to the mass spectrometry system. Elution was performed under $5 \%$ buffer B (95\% ACN, 0.1\% FA) for $5 \mathrm{~min}$, followed by a linear gradient for $35 \mathrm{~min}$ in which the proportion of buffer B increased from 5 to $35 \%$. The proportion was then increased to $60 \%$ for the next $5 \mathrm{~min}$, then increased to $80 \%$ over $2 \mathrm{~min}$ where it remained for $2 \mathrm{~min}$. Finally the proportion of buffer B was recovered to $5 \%$ over $1 \mathrm{~min}$ and balanced for 10 min. The machine used was a TripleTOF 5600 (AB SCIEX, Concord, ON) with a Nanospray IIIsource (AB SCIEX, Concord, ON) ion source and a quartz radiator (New Objectives, Woburn, MA).

\section{Bioinformatics analysis}

The database was used in this study: Uniprot_homo (127497sequences), link address: (http://www.uniprot. org/uniprot/?query=taxonomy:9606). The Software Mascot was used to identify protein, version Mascot2.3.02. It has been rated as the gold standard of biological mass spectrometry software by Frost/Sullivan research institutions. Gene Ontology (GO) database (http://www.gene ontology.org.) was used to classified the functional annotation of proteins into 3 categories: biological process, molecular function, and cellular component. The significant enrichment analysis of GO function was performed to identify GO terms that were significantly enriched in differentially expressed proteins. When the protein abundance ratio was more than 1.5 times and its $p$-value was less than 0.05 , the protein was regarded as the differential protein between different samples. The significant enrichment analysis of Pathway is based on KEGG Pathway to find out the significant enrichment of 
Pathway in differential proteins compared with all the identified protein backgrounds.

\section{Western blotting}

To validate the accuracy of iTRAQ results, western blot analysis was performed.

The plasma was diluted ten times by PBS. $30 \mu \mathrm{L}$ of samples per lane were loaded for $10 \%$ Bis-Tris polyacrylamide gels and then transferred onto PVDF membrane (Millipore, Billerica, MA) by electroblotting. The membranes were blocked in TBS 0.5\% Tween containing 5\% skim milk powder (OXOID, Basingstoke, UK) for $1 \mathrm{~h}$ at room temperature and incubated with primary antibody: anti-IGFBP4 (Abcam, Cambridge, UK) overnight at $4{ }^{\circ} \mathrm{C}$. Then the membranes were incubated with peroxidaseconjugated secondary antibodie (Bio-Rad, Hercules, USA) for $1 \mathrm{~h}$ at room temperature. The bands were visualized by using Millipore's enhanced chemiluminescence (ECL) with the Amersham Imager 600 detection system (GE, Boston, USA). The western blot results represent at least 2 independent biological replicates.

\section{Behavioral test}

Spatial learning and cognitive flexibility were evaluated using a Morris water maze (WMW) $[55,56]$, which consisted of a circular pool $(150 \mathrm{~cm}$ in diameter), filling with water maintained at room temperature $\left(23 \pm 1^{\circ} \mathrm{C}\right)$, opacified by adding nontoxic white. The platform (diameter in $15 \mathrm{~cm}$ ) was hidden $1 \mathrm{~cm}$ underneath the water surface in the middle of one fixed quadrant ('target') of the pool. Four different colors and dimensions visual cues were attached to the side of the pool equidistant from one another, and the pool was surrounded by a plain curtain to block any other visual cues. For training (day 1-5), mice were released randomly with their heads facing the pool wall from one of the four starting locations, and trained daily in four sequential sessions (15$30 \mathrm{~min}$ interval). Once mice were not able to locate the platform after $60 \mathrm{~s}$, they were manually placed on the platform and allowed to remain on it for $20 \mathrm{~s}$. For probe test (day 6), a $60 \mathrm{~s}$ probe trial was performed to assess the memory of the mice. The latency to locate the platform and velocity were recorded by EthoVision video tracking equipment and software (Noldus, Wageningen, The Netherlands).

\section{Statistical analysis}

The data are reported as the means $\pm \mathrm{SD}$, and statistical analysis between two groups was assessed using independent-samples t-tests or Mann-Whitney $\mathrm{U}$ tests. $p<0.05$ was considered statistically significant. All the statistical analyses were performed using SPSS software, version 22 (IBM, Armonk, USA) and GraphPad Prism, version 7 (GraphPad Software Inc.,San Diego, USA).

\section{Supplementary information}

Supplementary information accompanies this paper at https://doi.org/10. 1186/s12864-019-6089-z.

Additional file 1: Figure S1. Extended monkey plasma proteome dataset from iTRAQ shotgun analysis.

Additional file 2: Figure S2. Gene ontology (GO) annotation and functional classification of identified plasma proteins from all monkey samples. GO terms for cellular compartment (A), molecular function (B), and biological process (C).

Additional file 3: Table S1. Up-regulated proteins in aging of monkey. Additional file 4: Table S2. Down-regulated proteins in aging of monkey.

\section{Abbreviations}

DAVID: Database for Annotation, Visualization and Integrated Discovery2; GO: Gene Ontology; iTRAQ: isobaric tags for relative and absolute quantification; TNF-a: tumor necrosis factor a

\section{Acknowledgements}

We would like to thank Prof. Yongchan Chen (Kunming University of Science and Technology) for providing monkey blood.

\section{Authors' contributions}

$\mathrm{LHL}$ and ZYX conceived and designed the experiments, WH, ZXQ and SJY performed the experiments, WH, HDJ, SHT and LHL analyzed the data, ZEF contributed materials, and LHL prepared figures and/or tables, WH wrote the article and $\mathrm{LHL}$ and $\mathrm{ZYX}$ reviewed and edited the manuscript before submission. All authors have read and approved the final manuscript.

\section{Funding}

This work was supported by the Natural Science Foundation of China (Grant No. 81670463, 31671539 and 31370214). Publication costs are funded by these funding.

\section{Availability of data and materials}

The datasets used and/or analysed during the current study available from the corresponding author on reasonable request.

\section{Ethics approval and consent to participate}

The use of human and monkey plasma samples was reviewed and approved by Ethics Committee at Tongji Hospital, Tongji University School of Medicine (KYSB-2016-54).

\section{Consent for publication}

Not applicable.

\section{Competing interests}

The authors declare that the research was conducted in the absence of any commercial or financial relationships that could be construed as a potential conflict of interest.

\section{Author details}

${ }^{1}$ Department of Thoracic-Cardiovascular Surgery, Tongji Hospital, Tongji University School of Medicine, Shanghai, China. ${ }^{2}$ Translational Center for Stem Cell Research, Tongji Hospital, Tongji University School of Medicine, Shanghai 200065, China. ${ }^{3}$ College of Life Sciences, Key Laboratary of Xinjiang Phytomedicine Resource and Utilization of Ministry of Education, Shihezi University, Shihezi 832003, Xinjiang, China.

Received: 31 December 2018 Accepted: 9 September 2019 Published online: 11 October 2019

\section{References}

1. Lopez-Otin C, Blasco MA, Partridge L, Serrano M, Kroemer G. The hallmarks of aging. Cell. 2013;153(6):1194-217.

2. Fan X, Gaur U, Sun L, Yang D, Yang M. The growth differentiation factor 11 (GDF11) and Myostatin (MSTN) in tissue specific aging. Mech Ageing Dev. 2017;164:108-12. 
3. Gouspillou G, Bourdelmarchasson I, Rouland R, Calmettes G, Biran M, Deschodtarsac V, Miraux S, Thiaudiere E, Pasdois P, DJAc D. Mitochondrial energetics is impaired in vivo in aged skeletal muscle. Aging Cell. 2014;13(1):39.

4. Rubio-Ruiz ME, Perez-Torres I, Soto ME, Pastelin G, Guarner-Lans V. Aging in blood vessels. Medicinal agents FOR systemic arterial hypertension in the elderly. Ageing Res Rev. 2014;18:132-47.

5. Vida C, GonzÃ lez EM, De IFMJCPD. Increase of oxidation and inflammation in nervous and immune systems with aging and anxiety. Curr Pharm Des. 2014;20(29):4656-78

6. Tolppanen AM, Solomon A, Soininen H, Kivipelto MJJADJ. Midlife vascular risk factors and Alzheimer's disease: evidence from epidemiological studies. J Alzheimers Dis. 2012;32(3):531.

7. Compta Y, Ibarretxe-Bilbao N, Pereira JB, Junqué C, Bargalló N, Tolosa E, Valldeoriola F, Muñoz E, Camara A, Buongiorno M, et al. Grey matter volume correlates of cerebrospinal markers of Alzheimer-pathology in Parkinson's disease and related dementia. Parkinsonism Relat Disord. 2012;18(8):941-7.

8. Ferrucci L, Fabbri E. Inflammageing: chronic inflammation in ageing, cardiovascular disease, and frailty. Nat Rev Cardiol. 2018;15(9):505-22.

9. Liu G, Rogers J, Murphy CT, Rongo C. EGF signalling activates the ubiquitin proteasome system to modulate C. elegans lifespan. EMBO J. 2011;30(15): 2990-3003.

10. Bektas A, Schurman SH, Sen R, Ferrucci LJEG. Aging, inflammation and the environment, vol. 105; 2017.

11. Gorbunova V, Seluanov A, Zhang Z, Gladyshev VN, Vijg J. Comparative genetics of longevity and cancer: insights from long-lived rodents. Nat Rev Genet. 2014;15(8):531-40.

12. Datta A, Chai YL, Tan JM, Lee JH, Francis PT, Chen CP, Sze SK, Lai MKP. An iTRAQ-based proteomic analysis reveals dysregulation of neocortical synaptopodin in Lewy body dementias. Mol Brain. 2017;10(1):36.

13. Sen $P$, Shah PP, Nativio R, Berger SL. Epigenetic mechanisms of longevity and aging. Cell. 2016;166(4):822-39.

14. Vos MJ, Carra S, Kanon B, Bosveld F, Klauke K, Sibon OCM, Kampinga HHJAC. Specific protein homeostatic functions of small heat-shock proteins increase lifespan. Aging Cell. 2016;15(2):217-26.

15. Geyer PE, Holdt LM, Teupser D, Mann M. Revisiting biomarker discovery by plasma proteomics. Mol Syst Biol. 2017;13(9):942.

16. Castellano JM, Mosher Kl, Abbey RJ, McBride AA, James ML, Berdnik D, Shen JC, Zou B, Xie XS, Tingle M, et al. Human umbilical cord plasma proteins revitalize hippocampal function in aged mice. Nature. 2017;544(7651):488-92.

17. Villeda SA, Plambeck KE, Middeldorp J, Castellano JM, Mosher Kl, Luo J, Smith LK, Bieri G, Lin K, Berdnik D, et al. Young blood reverses age-related impairments in cognitive function and synaptic plasticity in mice. Nat Med. 2014;20(6):659-63.

18. Katsimpardi L, Litterman N K, Schein P A, et al. Vascular and Neurogenic Rejuvenation of the Aging Mouse Brain by Young Systemic Factors. Science. 2014;344(6184):630-34

19. Villeda SA, Luo J, Mosher Kl, Zou B, Britschgi M, Bieri G, Stan TM, Fainberg N, Ding Z, Eggel A, et al. The ageing systemic milieu negatively regulates neurogenesis and cognitive function. Nature. 2011;477(7362):90-4

20. Severino V, Alessio N, Farina A, Sandomenico A, Cipollaro M, Peluso G, Galderisi U, Chambery A. Insulin-like growth factor binding proteins 4 and 7 released by senescent cells promote premature senescence in mesenchymal stem cells. Cell Death Dis. 2013;4:e911.

21. Baxter RC. IGF binding proteins in cancer: mechanistic and clinical insights. Nat Rev Cancer. 2014;14(5):329-41.

22. Clemmons DR. Role of IGF binding proteins in regulating metabolism. Trends Endocrinol Metab. 2016;27(6):375-91.

23. Jones Jl, Gockerman A, Busby WH, Wright G, Clemmons DR. Insulin-like growth factor binding protein 1 stimulates cell migration and binds to the alpha 5 beta 1 integrin by means of its Arg-Gly-Asp sequence. Proc Natl Acad Sci U S A. 1993;90(22):10553-7.

24. Feng $\mathrm{N}$, Zhang Z, Wang Z, Zheng H, Qu F, He X, Wang C. Insulin-Like Growth Factor Binding Protein-2 Promotes Adhesion of Endothelial Progenitor Cells to Endothelial Cells via Integrin alpha5beta1. J Mol Neurosci. 2015;57(3):426-34.

25. Shen X, Xi G, Maile LA, Wai C, Rosen CJ, Clemmons DR. Insulin-like growth factor (IGF) binding protein 2 functions coordinately with receptor protein tyrosine phosphatase beta and the IGF-I receptor to regulate IGF-Istimulated signaling. Mol Cell Biol. 2012;32(20):4116-30.

26. Xi G, Shen X, Rosen CJ, Clemmons DR. IRS-1 functions as a molecular scaffold to coordinate IGF-I/IGFBP-2 signaling during osteoblast differentiation. J Bone Miner Res. 2016;31(6):1300-14.
27. Carter S, Li Z, Lemieux I, Almeras N, Tremblay A, Bergeron J, Poirier P, Deshaies Y, Despres JP, Picard F. Circulating IGFBP-2 levels are incrementally linked to correlates of the metabolic syndrome and independently associated with VLDL triglycerides. Atherosclerosis. 2014;237(2):645-51.

28. Gokulakrishnan K, Velmurugan K, Ganesan S, Mohan V. Circulating levels of insulin-like growth factor binding protein-1 in relation to insulin resistance, type 2 diabetes mellitus, and metabolic syndrome (Chennai urban rural epidemiology study 118). Metabolism. 2012;61(1):43-6.

29. Lewitt MS, Hilding A, Brismar K, Efendic S, Ostenson CG, Hall K. IGF-binding protein 1 and abdominal obesity in the development of type 2 diabetes in women. Eur J Endocrinol. 2010;163(2):233-42.

30. Wang Y, Nishida S, Boudignon BM, Burghardt A, Elalieh HZ, Hamilton MM, Majumdar S, Halloran BP, Clemens TL, Bikle DD. IGF-I receptor is required for the anabolic actions of parathyroid hormone on bone. J Bone Miner Res. 2007;22(9):1329-37.

31. Zhu W, Shiojima I, Ito Y, Li Z, Ikeda H, Yoshida M, Naito AT, Nishi J, Ueno H, Umezawa A, et al. IGFBP-4 is an inhibitor of canonical Wnt signalling required for cardiogenesis. Nature. 2008;454(7202):345-9.

32. Wu J, Wang C, Miao X, Wu Y, Yuan J, Ding M, Li J, Shi Z. Age-related insulinlike growth factor binding Protein-4 overexpression inhibits osteogenic differentiation of rat mesenchymal stem cells. Cell Physiol Biochem. 2017; 42(2):640-50

33. Wolman Marc A, Jain Roshan A, Marsden Kurt C, Bell H, Skinner J, Hayer Katharina E, Hogenesch John B, Granato M. A genome-wide screen identifies PAPP-AA-mediated IGFR signaling as a novel regulator of habituation learning. Neuron. 2015;85(6):1200-11.

34. Maridas DE, DeMambro VE, Le PT, Mohan S, Rosen CJ. IGFBP4 is required for Adipogenesis and influences the distribution of adipose depots. Endocrinology. 2017;158(10):3488-500.

35. Powers ET, Morimoto RI, Dillin A, Kelly JW, Balch WE. Biological and chemical approaches to diseases of proteostasis deficiency. Annu Rev Biochem. 2009;78:959-91.

36. Balch WE, Morimoto RI, Dillin A, Kelly JW. Adapting proteostasis for disease intervention. Science. 2008;319(5865):916-9.

37. Ben-Zvi A, Miller EA, Morimoto RI. Collapse of proteostasis represents an early molecular event in Caenorhabditis elegans aging. Proc Natl Acad Sci U S. 2009;106(35):14914-9.

38. Rubinsztein DC, Marino G, Kroemer G. Autophagy and aging. Cell. 2011; 146(5):682-95.

39. Tomaru U, Takahashi S, Ishizu A, Miyatake Y, Gohda A, Suzuki S, Ono A, Ohara J, Baba T, Murata S, et al. Decreased proteasomal activity causes agerelated phenotypes and promotes the development of metabolic abnormalities. Am J Pathol. 2012;180(3):963-72.

40. Zhang C, Cuervo AMJNM. Restoration of chaperone-mediated autophagy in aging liver improves cellular maintenance and hepatic function. Nat Med. 2008;14(9):959-65.

41. Harrison DE, Strong R, Sharp ZD, Nelson JF, Astle CM, Flurkey K, Nadon NL, Wilkinson JE, Frenkel K, Carter CS, et al. Rapamycin fed late in life extends lifespan in genetically heterogeneous mice. Nature. 2009:460(7253):392-5.

42. Blagosklonny MV. Rapamycin-induced glucose intolerance: hunger or starvation diabetes. Cell Cycle. 2011;10(24):4217-24.

43. Spong A, Bartke A. Rapamycin slows aging in mice. Cell Cycle. 2012;11(5):845.

44. Laplante M, Sabatini David M. mTOR signaling in growth control and disease. Cell. 2012;149(2):274-93.

45. Rando TA, Chang HY. Aging, rejuvenation, and epigenetic reprogramming: resetting the aging clock. Cell. 2012;148(1-2):46-57.

46. Russell SJ, Kahn CR. Endocrine regulation of ageing. Nat Rev Mol Cell Biol. 2007;8(9):681-91.

47. Zhang G, Li J, Purkayastha S, Tang Y, Zhang H, Yin Y, Li B, Liu G, Cai D. Hypothalamic programming of systemic ageing involving IKK-beta, NFkappaB and GnRH. Nature. 2013:497(7448):211-6.

48. Salminen A, Kaarniranta K, Kauppinen AJA. Inflammaging: disturbed interplay between autophagy and inflammasomes. Aging (Albany NY). 2012; 4(3):166-75.

49. Franceschi C, Bonafè M, Valensin S, Olivieri F, De LM, Ottaviani E, De Benedictis $\mathrm{G}$. Inflamm-aging. An evolutionary perspective on immunosenescence. Ann N Y Acad Sci. 2010;908(1):244-54.

50. Barzilai N, Huffman DM, Muzumdar RH, Bartke A. The critical role of metabolic pathways in aging. Diabetes. 2012;61(6):1315-22.

51. Tabas I. Macrophage death and defective inflammation resolution in atherosclerosis. Nat Rev Immunol. 2010;10(1):36-46. 
52. Geyer PE, Kulak NA, Pichler G, Holdt LM, Teupser D, Mann M. Plasma proteome profiling to assess human health and disease. Cell Syst. 2016;2(3): 185-95.

53. Moulder R, Bhosale SD, Goodlett DR, Lahesmaa R. Analysis of the plasma proteome using ITRAQ and TMT-based isobaric labeling. Mass Spectrom Rev. 2018;37(5):583-606.

54. Tanaka T, Biancotto A, Moaddel R, Moore AZ, Gonzalez-Freire M, Aon MA, Candia J, Zhang P, Cheung F, Fantoni G, et al. Plasma proteomic signature of age in healthy humans. Aging Cell. 2018;17(5):e12799.

55. Vorhees CV, Williams MT. Morris water maze: procedures for assessing spatial and related forms of learning and memory. Nat Protoc. 2006;1(2): 848-58.

56. Zhan G, Yang N, Li S, Huang N, Fang X, Zhang J, Zhu B, Yang L, Yang C, Luo AJA. Abnormal gut microbiota composition contributes to cognitive dysfunction in SAMP8 mice. Aging (Albany NY). 2018;10(6):1257-67.

\section{Publisher's Note}

Springer Nature remains neutral with regard to jurisdictional claims in published maps and institutional affiliations.

Ready to submit your research? Choose BMC and benefit from:

- fast, convenient online submission

- thorough peer review by experienced researchers in your field

- rapid publication on acceptance

- support for research data, including large and complex data types

- gold Open Access which fosters wider collaboration and increased citations

- maximum visibility for your research: over $100 \mathrm{M}$ website views per year

At BMC, research is always in progress.

Learn more biomedcentral.com/submissions 